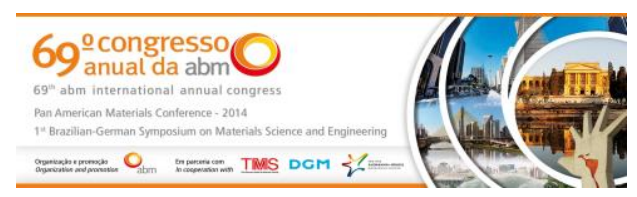

Tema: Soldagem

\title{
EFEITO DA ENERGIA DE SOLDAGEM NA MICROESTRUTURA E RESISTENCIA À CORROSÃO DO AÇO INOXIDÁVEL SUPERDUPLEX UNS S32750 PELO PROCESSO TIG*
}

\section{Resumo}

Francisco Necy Alves Júnior ${ }^{1}$ Everton Barbosa Nunes ${ }^{2}$ Alexandre Sousa Barreto ${ }^{3}$ Delaney Gomes Marques 4 Marcelo Ferreira Motta ${ }^{5}$

Os aços inoxidáveis superduplex (AISD) aliam boas propriedades mecânicas e resistência à corrosão, possuindo um vasto campo de aplicação na indústria petroquímica. Geralmente, os reparos dos equipamentos são realizados por soldagem, sendo importante a seleção de parâmetros. É de suma importância a obtenção do teor adequado de ferrita no metal de solda, sendo que a variação da energia de soldagem pode influenciar de forma direta a microestrutura e resistência à corrosão. Logo, este trabalho teve como objetivo avaliar os efeitos provenientes da variação de parâmetros de soldagem nas características do AISD UNS S32750. Foi avaliado o balanço de fases, relacionando esse efeito com a resistência à corrosão. Foram realizadas soldagens em chapas pelo processo TIG autógeno em 3 níveis de energia de soldagem $(5,10$ e $18 \mathrm{~kJ} / \mathrm{cm}$ ), variando a corrente e velocidade de soldagem, de modo a obter 5 condições e a possibilidade de analisar as variáveis-resposta com essas variações isoladamente. $A$ análise da microestrutura foi realizada por microscopia ótica e o teor de ferrita foi quantificado pela utilização de duas técnicas: ferritoscópio e quantificação por imagem. Foram realizados ensaios de temperatura crítica de pite para análise de resistência à corrosão. Concluiu-se então que o acréscimo de energia pela variação da velocidade de soldagem acarretou no aumento no teor de ferrita, ocasionando a redução da temperatura crítica de pite, sendo estes observados na fase ferrítica.

Palavras-chave: Soldagem; Superduplex; Corrosão; TIG.

\section{EFFECT OF ENERGY WELDING ON MICROSTRUCTURE AND CORROSION RESISTANCE OF SUPERDUPLEX STAINLESS STELL UNS S32750 BY GTAW PROCESS}

\section{Abstract}

The superduplex stainless steel (SDSS) combine good mechanical properties and corrosion resistance, having a wide field of application in the petrochemical industry. Usually, the repairs of the equipment are made by welding, so the selection of parameters it is important. It is extremely important to obtain adequate ferrite content in the weld metal, and the variation of the welding energy can directly influence the microstructure and corrosion resistance. Therefore, this study aimed to evaluate the effects from the variation of welding parameters on the characteristics of SDSS UNS S32750. The rate phase was evaluated by relating this effect to the corrosion resistance. Welding in plates are made by GTAW autogenous process on 3 levels $(5,10,18 \mathrm{~kJ} / \mathrm{cm})$, varying the current and welding speed so as to obtain 5 conditions and the possibility to analyze the response variables with this parameters alone. The microstructure analysis was carried out by optical microscopy and ferrite content was quantified by using two techniques: ferritoscope and imaging quantification. The test of critical temperature for pitting are made for analyses the corrosion resistance. It was concluded that the addition of energy by varying the welding speed resulted in an increase in ferrite content and a decrease of the critical pitting temperature, which are observed in the ferritic phase.

Keywords: Welding; Superduplex; Corrosion; GTAW.

1 Engenheiro metalurgista, mestrando em ciência dos materiais, Depto. Eng. Metalúrgica e de Materiais, Universidade Federal do Ceará (UFC), Instrutor Educacional Superior, setor metalurgista, Senai-CE, CET AFR, Maracanaú, CE, Brasil.

2 Engenheiro mecânico, mestre, doutorando em ciência dos materiais, Depto. de Eng. Metalúrgica e de Materiais, UFC, Fortaleza, CE, Brasil.

3 Eng. mecânico, mestrando em ciência dos materiais, Depto. Eng. Met. e Mat., UFC, Fortaleza, CE, Brasil.

4 Graduando, Engenharia metalúrgica, Depto. Eng. Met. e Mat., UFC, Fortaleza, CE, Brasil.

5 Engenheiro mecânico, doutor, professor e pesquisador em ciência dos materiais, Depto. Engenharia Metalúrgica e de Materiais, UFC, Fortaleza, CE, Brasil.

\footnotetext{
* Contribuição técnica ao 69 Congresso Anual da ABM - Internacional e ao 14ํ ENEMET - Encontro Nacional de Estudantes de Engenharia Metalúrgica, de Materiais e de Minas, 21 a 25 de julho de 2014, São Paulo, SP, Brasil.
} 


\section{INTRODUÇÃO}

Os aços inoxidáveis duplex (AID) foram desenvolvidos na década de 1930, com o objetivo de solucionar os problemas de corrosão intragranular dados nos aços inoxidáveis austeníticos em ambientes de maior agressividade. Devido a isso, em várias aplicações foram substituindo os austeníticos e com isso sua comercialização foi avançando [1].

A partir de então, problemas ocorrentes nestes materiais foram surgindo devido o mau controle na fabricação e manutenção. Com isso, foram desenvolvidos estudos e modificações visando melhorias nesses materiais, e dentre esses desenvolvimentos, surgiram os aços inoxidáveis superduplex (AISD). Em estudos mais recentes, vem sendo abordado à questão econômica, tendo em vista que estes materiais possuem altos teores de elementos de liga ( $\mathrm{Cr}$ e $\mathrm{Ni}$ ). Para isso, a utilização de maiores teores de $\mathrm{N}$ são dadas em função de estabilizar a austenita, diminuindo o teor de Ni nestes materiais [2].

Os aços inoxidáveis superduplex (AISD) são subclasses dos aços inoxidáveis duplex, possuindo elevada resistência mecânica, bem com alta resistência à corrosão. Características essas, adquiridas por aliar os benefícios decorrentes das fases presentes, ferrita $(\delta)$ e austenita $(\gamma)[3]$. Por serem aços nobres e classificados como especiais, as suas aplicações são específicas em ambientes mais agressivos. Tendo em vista esse fato, se fazem necessários estudos aprofundados visando o aperfeiçoamento das características desses materiais. Geralmente são utilizados em equipamento de indústrias petroquímicas, trocadores de calor, usinas de dessalinização e etc.

A soldagem é um dos processos mais utilizados na fabricação e manutenção desses equipamentos. Porém uma soldagem inadequada pode adicionar defeitos ao componente, que pode desencadear uma série de problemas. Estudos realizados por pesquisadores, como o trabalho realizado por Nunes em 2009 [4], mostraram resultados distintos ao selecionar os parâmetros de soldagem (corrente e velocidade) quanto ao balanceamento de fases. Esse balanceamento pode ser considerado aceitável quando o teor de ferrita obedece à faixa de $35-65 \%$, segundo estudos realizados por Eckenrod e Pinnow em 1984 [5]. Por esse motivo torna-se importante o estudo dos seus efeitos nas características metalúrgicas, associando aos comportamentos à corrosão.

O ciclo térmico gerado pela soldagem pode proporcionar à precipitação de fases, como também modificar a razão $\delta / \gamma$. Tendo em vista que nos AIDs a energia de soldagem está ligada diretamente com a variação da razão, outras propriedades podem ser afetadas, como por exemplo a resistência à corrosão e propriedades mecânicas.

Nesse contexto, esse trabalho foi fundamentado com o objetivo de avaliar os efeitos dos parâmetros de soldagem no balanceamento de fases e sua influência na resistência à corrosão no aço inoxidável superduplex UNS S32750 (SAF 2507).

\section{MATERIAIS E MÉTODOS}

Foram realizadas combinações das variáveis de controle (corrente e velocidade de soldagem), e para extrair resposta quanto aos efeitos dessas variáveis, foram feitos ensaios de corrosão (CPT), bem como quantificação de ferrita por ferritoscópio e por imagem.

\footnotetext{
* Contribuição técnica ao 69ำ Congresso Anual da ABM - Internacional e ao 14ํㅡㄹ ENET - Encontro Nacional de Estudantes de Engenharia Metalúrgica, de Materiais e de Minas, 21 a 25 de julho de 2014 , São Paulo, SP, Brasil.
} 


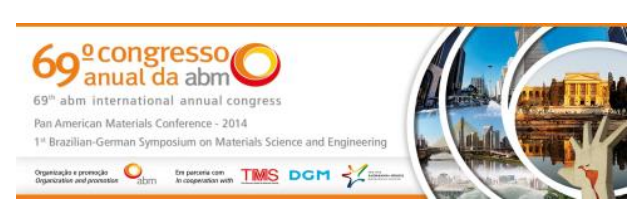

\subsection{Caracterização do Material como Recebido}

Foi realizada uma simples caracterização metalográfica no material base, para verificar a condição inicial do material. O modo de caracterização será descrito abaixo no tópico de preparação de amostras.

\subsection{Preparação dos Corpos de Prova}

Nesta etapa as chapas foram cortadas na dimensão de $100 \times 50 \times 24 \mathrm{~mm}$, de modo que a maior dimensão é coincidente com o sentido de laminação. Para o auxílio no corte das chapas na dimensão adequada, foi utilizada a cortadeira de serra fita STARRET.

\subsection{Soldagem}

As soldagens foram realizadas utilizando o processo TIG autógeno com corrente contínua, ou seja, sem adição de material, com auxílio da fonte inversal IBM Digiplus A7. Utilizou-se como gás de proteção o argônio puro na vazão de $15 \mathrm{l} / \mathrm{min}$, e eletrodo de tungstênio com adição de óxido de Th de 2,4 mm. A DPEP (distancia da ponta do eletrodo para a peça) foi de $4 \mathrm{~mm}$. Foi utilizado o gás argônio puro para que nenhuma influência de gás fosse interferir nos resultados e o eletrodo toriado é o mais bem indicado para soldagem TIG CC-, eletrodo com polaridade negativa.

As condições de soldagem foram escolhidas de modo a avaliar os efeitos da corrente e velocidade de soldagem, variando a energia nominal de soldagem em três níveis. Foram utilizados 3 níveis de correntes $(115,200$ e 300 A), e 3 de velocidades $(11,4$, 20 e $40 \mathrm{~cm} / \mathrm{min}$ ), resultando em 5 condições de soldagem com energias de soldagem de 5,10 e $18 \mathrm{~kJ} / \mathrm{cm}$. A definição dos parâmetros foi dada de modo a ser possível analisar a variação da energia de soldagem pela alteração da corrente (técnica tipo I) ou pela velocidade de soldagem (técnica Tipo V). As tensões médias nas condições soldadas foram entre $17-20$ Volts. A Tabela 1 mostra os parâmetros utilizados nas 5 condições.

Tabela 1. Parâmetros de soldagem

\begin{tabular}{lcccccc}
\hline \multicolumn{2}{l}{ Técnica } & Ensaio & Vs (cm/min) & I (A) & $\mathrm{U}(\mathrm{V})$ & $\mathrm{E}(\mathrm{kJ} / \mathrm{cm})$ \\
\hline \multirow{2}{*}{ Tipo V } & I2V3 & 11,4 & 200 & 17,3 & 18,3 \\
\cline { 2 - 7 } & I1V2 & 40 & 200 & 16,9 & 5,0 \\
\hline \multirow{2}{*}{ Tipo V } & Tipo I & I2V2 & 20 & 200 & 17,6 & 10,5 \\
\hline \multirow{2}{*}{ Tipo I } & I3V2 & 20 & 115 & 14,5 & 5,0 \\
\cline { 2 - 6 } & I2V1 & 20 & 300 & 20,1 & 18,09 \\
\hline
\end{tabular}

\subsection{Corte e Preparação Metalográfica}

O sentido da soldagem foi o mesmo coincidente com o eixo maior da chapa. As amostras foram tiradas da chapa de modo a analisar a sessão longitudinal da solda, escolhida assim por possuir maior área para analise da zona fundida. A Figura 1 mostra o esquema do corpo de prova soldado e as amostras retiradas para os ensaios.

* Contribuição técnica ao 69ํㅡㄹ Congresso Anual da ABM - Internacional e ao 14º ENEMET - Encontro Nacional de Estudantes de Engenharia Metalúrgica, de Materiais e de Minas, 21 a 25 de julho de 2014 , São Paulo, SP, Brasil. 


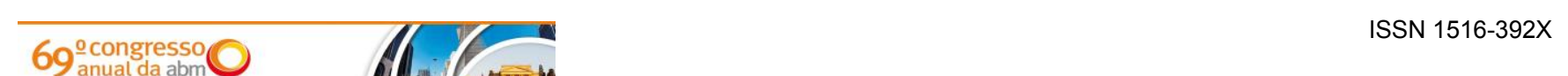

D DCM

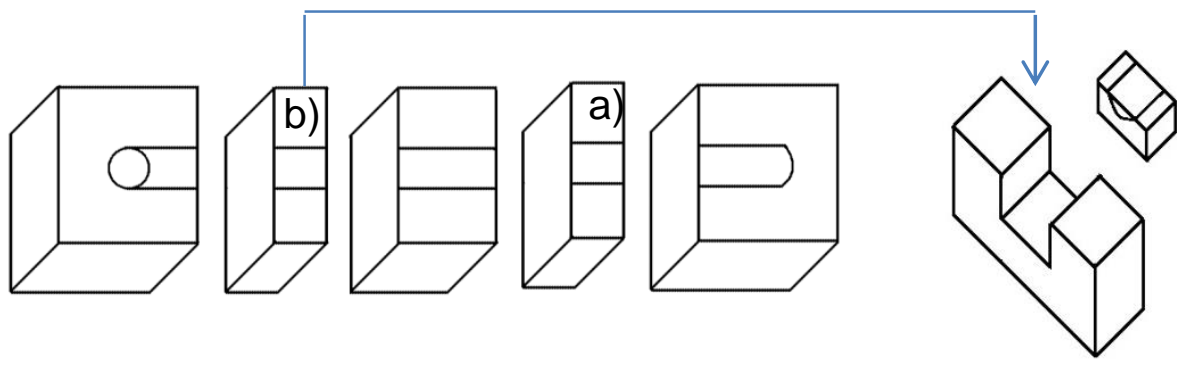

Figura 1. Esquema de soldagem e corte das amostras

As amostras denominadas "a" foram preparadas metalograficamente por procedimento comum de lixamento, polimento e ataque químico com Behara modificado à temperatura de $60^{\circ} \mathrm{C}$. Para a captação de imagens, foi utilizado ao microscópio ótimo OLYMPUS GX41 acoplado a um computador com software ImagePro Plus v.6.0.

As amostras "b", conforme foram cortadas eliminando a parte excessiva de metal base, embutidas em resina acrílica de cura a frio com um frio de cobre em contato, de modo que fosse possível um contato elétrico. Esse modo de preparo foi feito para os ensaios de corrosão, CPT.

\subsection{Quantificação das Fases}

A quantificação foi feita em dois modos: por ferritoscópio e por imagem. Durante a etapa de lixamento (após a lixa de 100 mesh), a amostra passou por quantificação de fases por ferritoscópio, onde foram feitas 25 medidas para cada condição, considerando um intervalo de confiança de 95\% na avaliação estatística dos resultados. Esse ensaio consiste em quantificar um determinado volume do material por meio de indução magnética. O aparelho utilizado foi o ferritoscópio Fischer MP23. Foi utilizado o método de avaliação estatística dos resultados pelo programa Origin, usando o Anova.

Após a obtenção das imagens da microestrutura por meio do microscópio ótico, estas foram tratadas pelo software ImageJ (versão 1.46r) visando obter o teor das fases na área dada pela imagem. Foram analisadas 25 imagens para cada condição de soldagem.

\subsection{Ensaio de polarização CPT}

Este ensaio foi feito baseado na norma ASTM G 150, que determina os parâmetros do ensaio para a obtenção da Temperatura Crítica de Pite (CPT), utilizando um potenciostato com controle na varredura da temperatura. A amostra foi imersa em uma solução eletrolítica de $1 \mathrm{M} \mathrm{NaCl}$ dentro de uma célula específica com a possibilidade de aquecimento gradativo de $1^{\circ} \mathrm{C} / \mathrm{min}$.

Durante o ensaio, é aplicada uma tensão constante de modo que a amostra (ânodo) é polarizada. Foi utilizado $700 \mathrm{mV}$ de tensão, devido ser recomentado para aços inoxidáveis. Foi registrado a variação da densidade de corrente $\left(\mathrm{mA} / \mathrm{cm}^{2}\right) \mathrm{com} o$ aumento da temperatura e tempo. A temperatura crítica de pite é observada quando a densidade de corrente se estabelece acima de $100 \mu \mathrm{A} / \mathrm{cm}^{2}$ por pelo menos 1 minuto, segundo a norma ASTM G 150 [6]. 


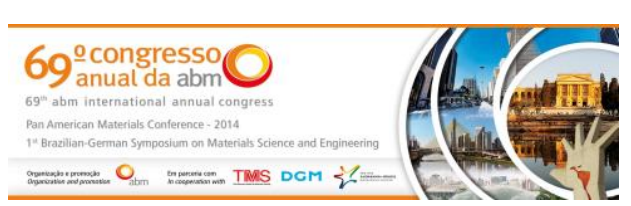

\section{RESULTADOS E DISCUSSÃo}

A seguir serão apresentados os resultados referentes aos ensaios explorados, visando relacionar as variáveis de controle com as respostas esperadas.

\subsection{Quantificação de Fases - Método do ferritoscópio}

A técnica de análise utilizando o ferritoscópio na Zona Fundida (ZF) gerou os seguintes resultados apresentados na Tabela 2. A Figura 3 também dispõe os resultados na forma de gráfico, levando em conta as técnicas de variação de energia de soldagem pela corrente (Tipo I) e pela velocidade de soldagem (Tipo V).

Tabela 2. Teor de ferrita na ZF segundo ferritoscópio.

\begin{tabular}{lcc}
\hline Energia & Condição & Teor de Ferrita \\
\hline \multirow{2}{*}{ E1 } & $\mathrm{I}$ 2V3 & $57,64 \% \pm 0,23 \%$ \\
\cline { 2 - 3 } & $\mathrm{I} 1 \mathrm{~V} 2$ & $54,91 \% \pm 1,29 \%$ \\
\hline E2 & $\mathrm{I} 2 \mathrm{~V} 2$ & $62,20 \% \pm 1,16 \%$ \\
\hline \multirow{2}{*}{ E3 } & $\mathrm{I} \mathrm{V} 2$ & $58,92 \% \pm 0,63 \%$ \\
\cline { 2 - 3 } & $\mathrm{I} 2 \mathrm{~V} 1$ & $70,40 \% \pm 1,21 \%$ \\
\hline
\end{tabular}

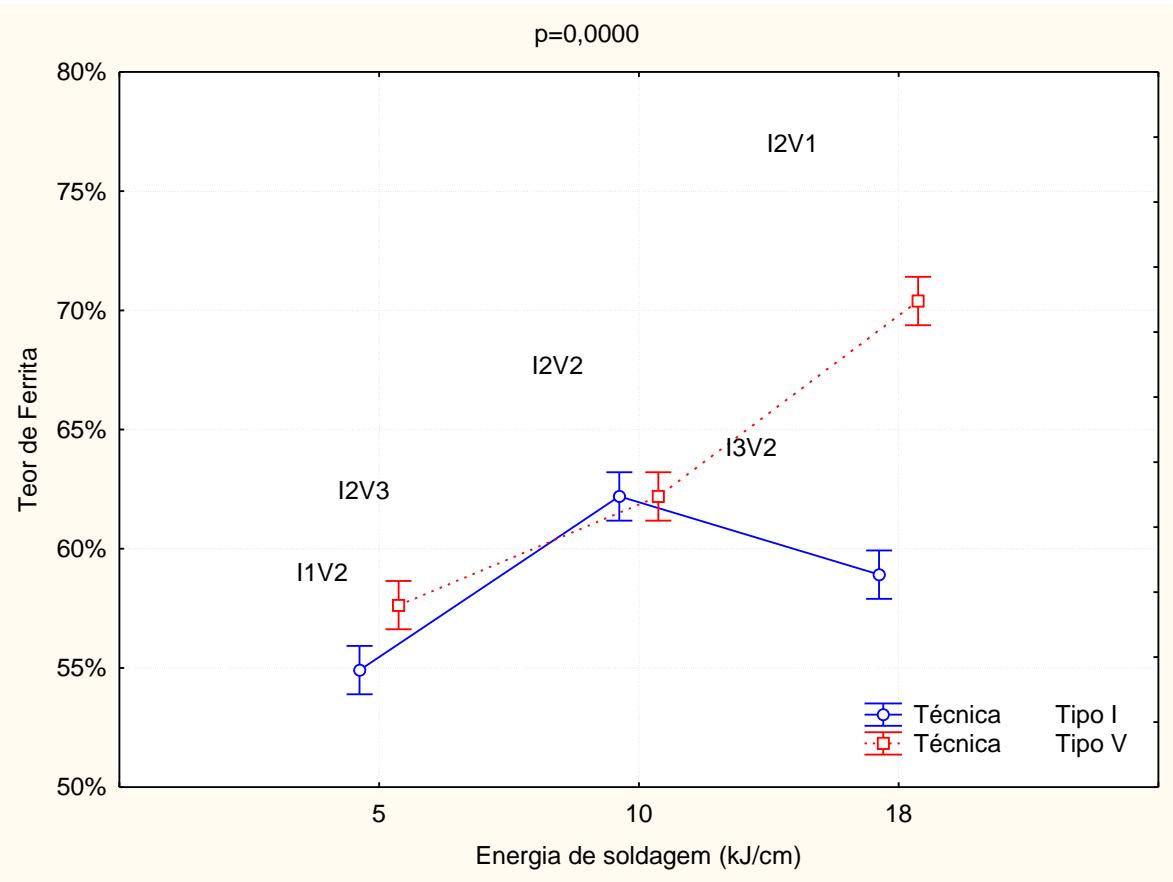

Figura 3. Gráfico da quantificação de ferrita nas condições soldadas segundo o ferritoscópio.

Foi verificado aumento do teor de ferrita com o aumento da energia de soldagem utilizando a técnica Tipo $\mathrm{V}$. Porém para a técnica Tipo I houve uma tendência a aumentar a fração de ferrita $(\delta)$ ao elevar a energia de 5 para $10 \mathrm{~kJ} / \mathrm{cm}$. Ao continuar elevando o nível de energia para esta técnica, o efeito não foi o mesmo, tendendo a diminuir o teor de ferrita.

Segundo a literatura, esperava-se que o teor de $\delta$ nos dois modos (Tipo I e $V$ ) fossem decrescendo com o aumento da energia de soldagem, devido ao gradiente de resfriamento que interfere positivamente na precipitação de austenita a partir da ferrita. Porém no método de análise Tipo V, observou-se uma tendência considerável de aumento no teor de ferrita. Esse fenômeno também foi verificado por Nunes [4],

* Contribuição técnica ao 69ํㅡㄹ Congresso Anual da ABM - Internacional e ao 14º ENEMET - Encontro Nacional de Estudantes de Engenharia Metalúrgica, de Materiais e de Minas, 21 a 25 de julho de 2014 , São Paulo, SP, Brasil. 


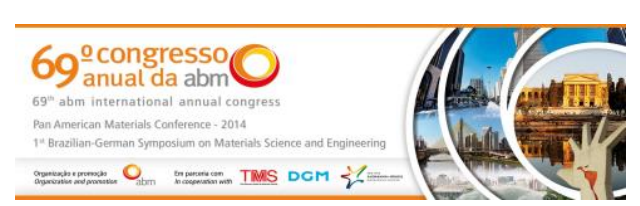

onde o teor de ferrita tendia a aumentar com o aumento da energia pela redução da velocidade de soldagem para faixas de soldagens entre $6-15 \mathrm{~kJ} / \mathrm{cm}$. Outro fator que pode ser preponderante foi o fato de as soldagens serem realizadas em chapa grossa, com condições de resfriamento tridimensionais, o que proporciona resfriamento rápido mesmo para condições de alto nível de energia de soldagem. Com isso, o efeito do resfriamento dado pela variação da energia pôde ter sido inibido, dando espaço a outro agente: perda de nitrogênio. GARCIA em 2011 [7] verificou perda de nitrogênio em soldas realizadas com TIG autógeno e argônio puro como gás de proteção, devido à diferença de pressão de nitrogênio na poça de fusão e o ambiente externo de proteção (Ar puro).

\subsection{Quantificação de Fases - Método de Análise por Imagem}

Nessa técnica assume-se que o percentual em área de uma fase é aproximadamente igual ao percentual em volume, conforme dito na norma ASTM E 1245-03 [8]. A imagem obtida por microscopia ótica tratadas pelo software ImageJ, onde os tons de cinza são segmentados e uma imagem é formada basicamente por duas cores. Houve então uma diferença de em média $11 \%$ entre os modos de quantificação. Isso pode ser devido aos fatores de correção dos dois métodos, tendo que o ferritoscópio mede a fração magnética de um volume, já o programa ImageJ quantifica a fração escura em uma imagem, não diferenciando fases intermetálicas e muitas vezes contornos de grão. A Figura 4 mostra exemplos de imagens tratadas e suas respectivas originais.
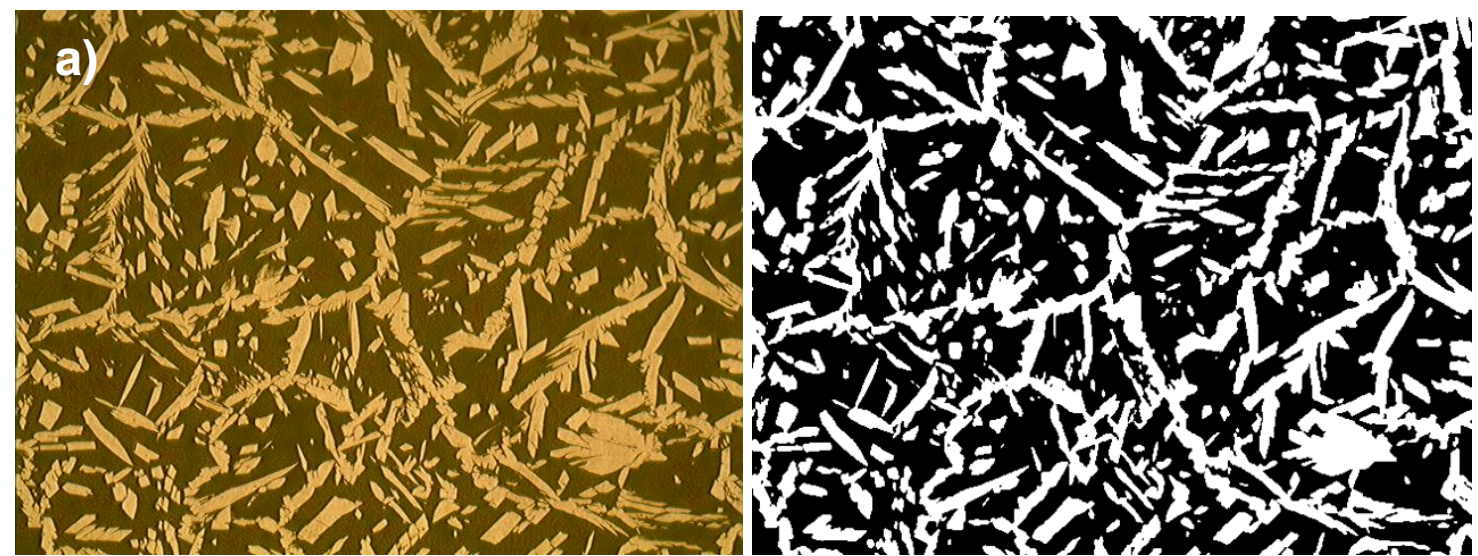

Figura 4. Exemplos de quantificação pelo ImageJ.a) ZF da condição I1V2; b) ZF da condição I2V1, ataque com Behara modificado).

Os resultados obtidos por imagem seguem na Tabela 3. Também dado o gráfico na Figura 5 onde se pôde verificar a diferença entre a detecção do teor de ferrita entre os dois métodos, porém a tendência entre as condições, segundo o teor de ferrita, foi mantida.

Tabela 3. Teor de ferrita na ZF segundo imagem por microscopia ótica (MO).

\begin{tabular}{lcc}
\hline Energia & Condição & Teor de Ferrita \\
\hline \multirow{2}{*}{ E1 } & I2V3 & $70,27 \pm 0,57 \%$ \\
\cline { 2 - 3 } & I1V2 & $64,00 \pm 0,43 \%$ \\
\hline E2 & I2V2 & $74,60 \pm 1,29 \%$ \\
\hline \multirow{2}{*}{ E3 } & I3V2 & $73,13 \pm 0,81 \%$ \\
\cline { 2 - 3 } & I2V1 & $77,78 \pm 0,75 \%$ \\
\hline
\end{tabular}

\footnotetext{
* Contribuição técnica ao 69ำ Congresso Anual da ABM - Internacional e ao $14^{\circ}$ ENEMET - Encontro Nacional de Estudantes de Engenharia Metalúrgica, de Materiais e de Minas, 21 a 25 de julho de 2014, São Paulo, SP, Brasil.
} 

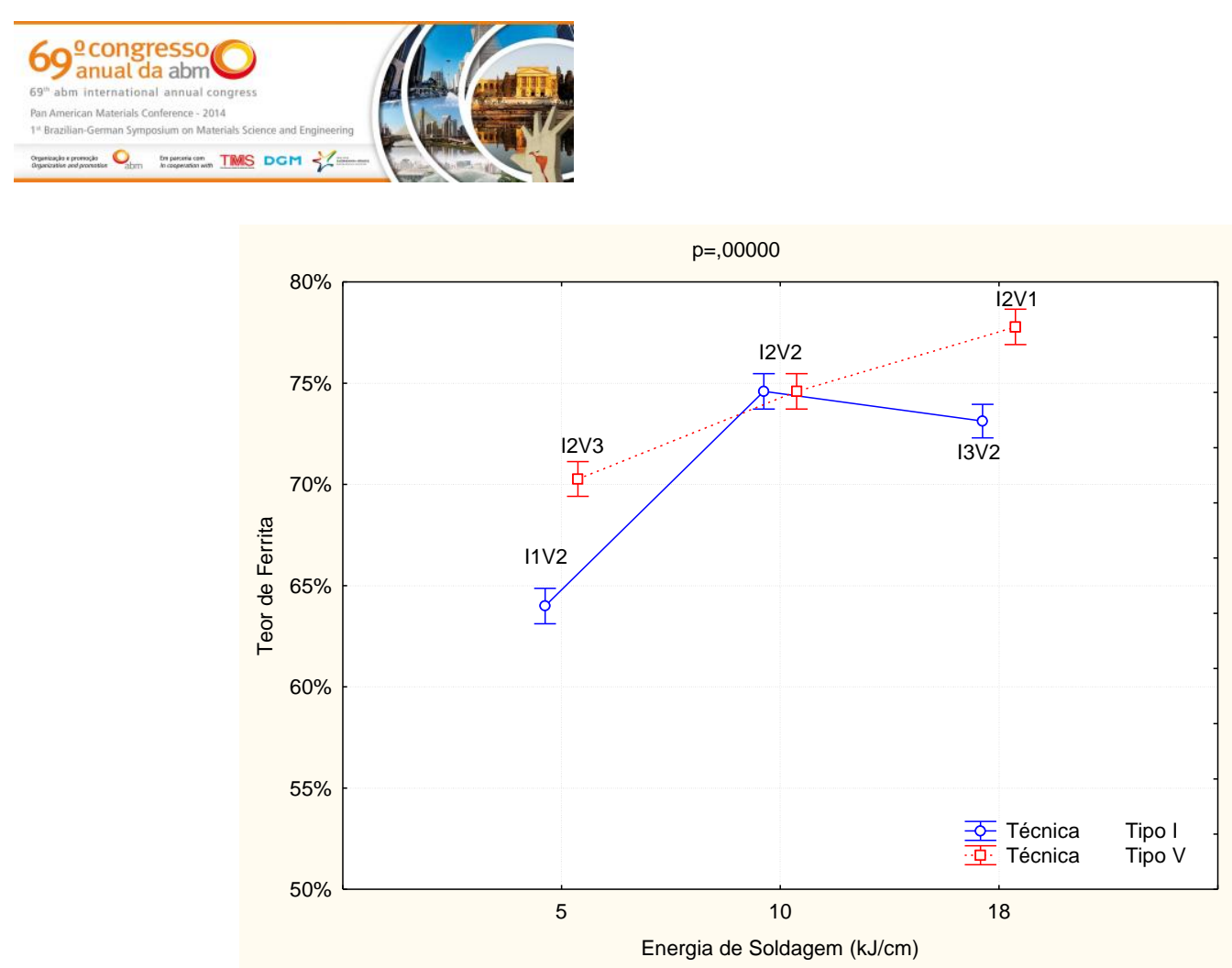

Figura 5. Gráfico da quantificação de ferrita nas condições soldadas segundo imagem.

Pode-se ver que entre as condições I2V2 e I3V2 há uma tendência à diminuição do teor de $\delta$, porém estatisticamente não há significância. Pode-se ver que há nivelamento nas barras de dispersão, tornando inviável afirmar que há uma diminuição significativa pelo aumento da energia utilizando a técnica tipo I. O gráfico na Figura 5 mostra as condições isoladamente.

\subsection{Ensaio CPT}

Abaixo seguem os resultados obtidos nos ensaios CPT, onde foi analisada a resistência à corrosão por pites das amostras soldadas. A Tabela 4 mostra os resultados agrupados para as condições estudadas. Também são dados em seguida exemplos de gráficos extraídos nos ensaios e o destaque para a região onde se iniciou os pite.

Tabela 4. Tabela de valores CPT para as condições.

\begin{tabular}{lccc}
\hline Condição & CPT $\left({ }^{\circ} \mathrm{C}\right)$ & Condição & CPT $\left({ }^{\circ} \mathrm{C}\right)$ \\
\hline I1V2 & $\sim 66,5$ & I2V1 & $\sim 61,0$ \\
\hline I2V3 & $\sim 68,1$ & I3V2 & $\sim 64,7$ \\
\hline I2V2 & $\sim 59,5$ & MB & $>80,0$ \\
\hline
\end{tabular}


Figura 6. Gráfico CPT para a condição I2V1 (aumento da região do gráfico).

* Contribuição técnica ao 69 Congresso Anual da ABM - Internacional e ao 14ํㅡㄹ ENEMET - Encontro Nacional de Estudantes de Engenharia Metalúrgica, de Materiais e de Minas, 21 a 25 de julho de 2014, São Paulo, SP, Brasil. 


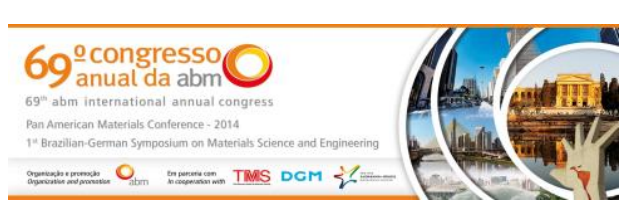

Apesar de os valores obtidos serem próximos, pode-se identificar uma tendência à diminuição da CPT com o aumento do teor de ferrita. Tendo em vista que as condições I2V2 e I2V1 obtiveram maiores teores de ferrita, 75 e $77 \%$ respectivamente (quantificação por imagem), essas apresentaram menores valores de CPT em relação às demais. Esse resultado também foi observado por WILL em 2009 [9], no qual a condição de aporte térmico próxima a $1 \mathrm{~kJ} / \mathrm{cm}$, com maior teor de ferrita e menor teor de nitrogênio, apresentou menor nível de CPT.

Pôde-se ver que a condição normal (MB) não sofreu abertura de pite crítica, pois a densidade de corrente somente ultrapassou o valor de $100 \mu \mathrm{A}$ por pouco tempo, e então repassivava a abertura do pite. Esse fenômeno é chamado de pite metaestável, onde não ocorre a abertura definitiva do pite. Com isso pode-se assumir que o MB possui valor CPT próximo a $80^{\circ} \mathrm{C}$, dado pela literatura tanto para o aço UNS S32750 como para o Zeron 100 [9].

O gráfico abaixo mostra as tendências relacionadas ao teor de ferrita e CPT.

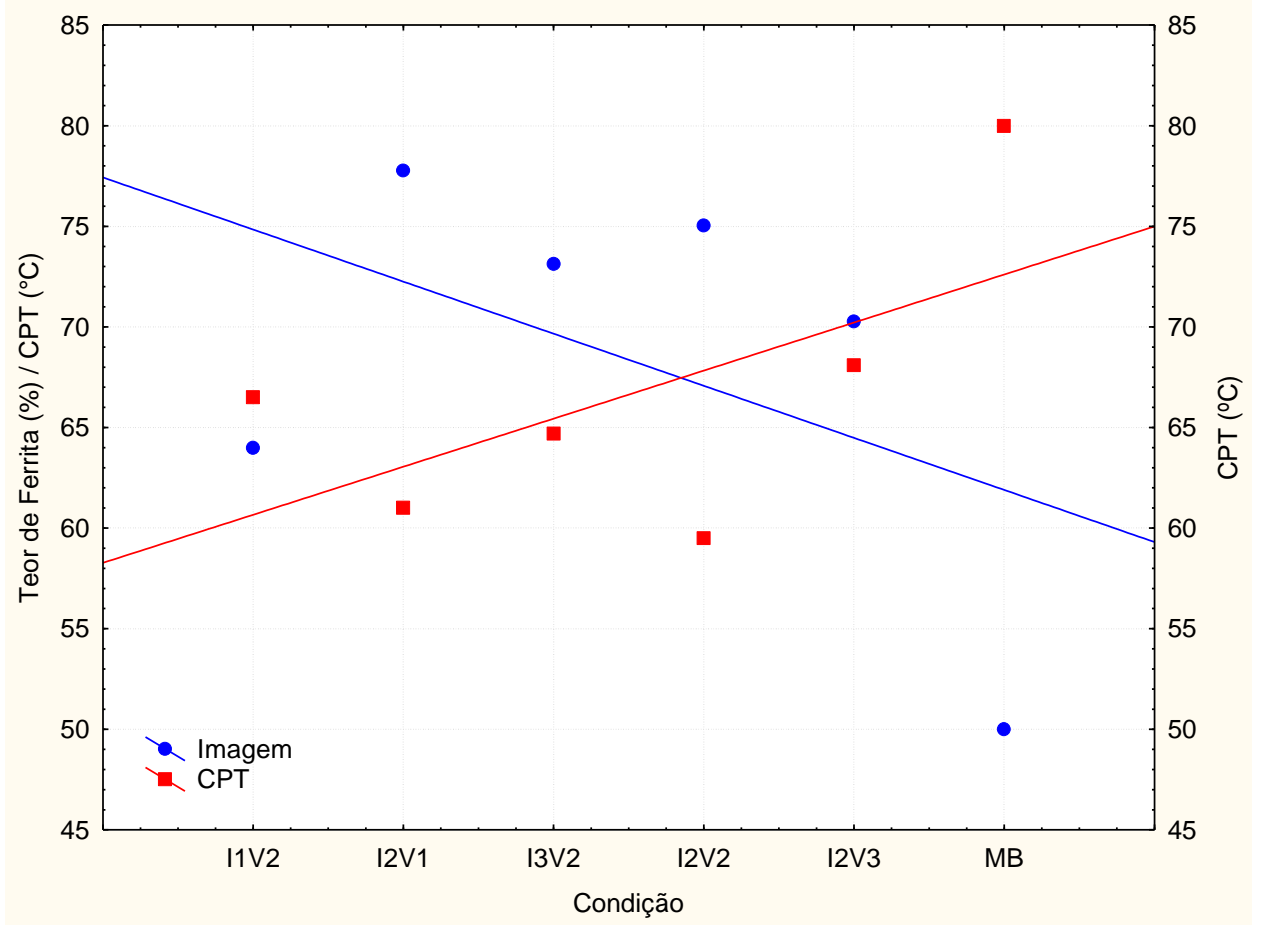

Figura 7. Gráfico de comparação do teor de ferrita com CPT para as condições de soldagem.

Foram retiradas fotos micrográficas dos pites gerados no ensaio CPT. O resultado visto foi que a ferrita é menos resistente a corrosão em comparação com a austenita. Isso pode ser devido à presença de nitretos observados dentro dos grãos de ferrita, fragilizando-os mesmo na ZF $[10,11]$. Pode ver ao fundo do pite após o ataque químico os grãos de austenita mais resistentes à corrosão. Vale salientar que esse fenômeno foi visto em todas as condições.

As Figuras 8 e 9 mostram a abertura do pite nas condições I1V2 e I2V1, respectivamente.

* Contribuição técnica ao 69 Congresso Anual da ABM - Internacional e ao 14ํㅡㄹ ENEMET - Encontro Nacional de Estudantes de Engenharia Metalúrgica, de Materiais e de Minas, 21 a 25 de julho de 2014, São Paulo, SP, Brasil. 

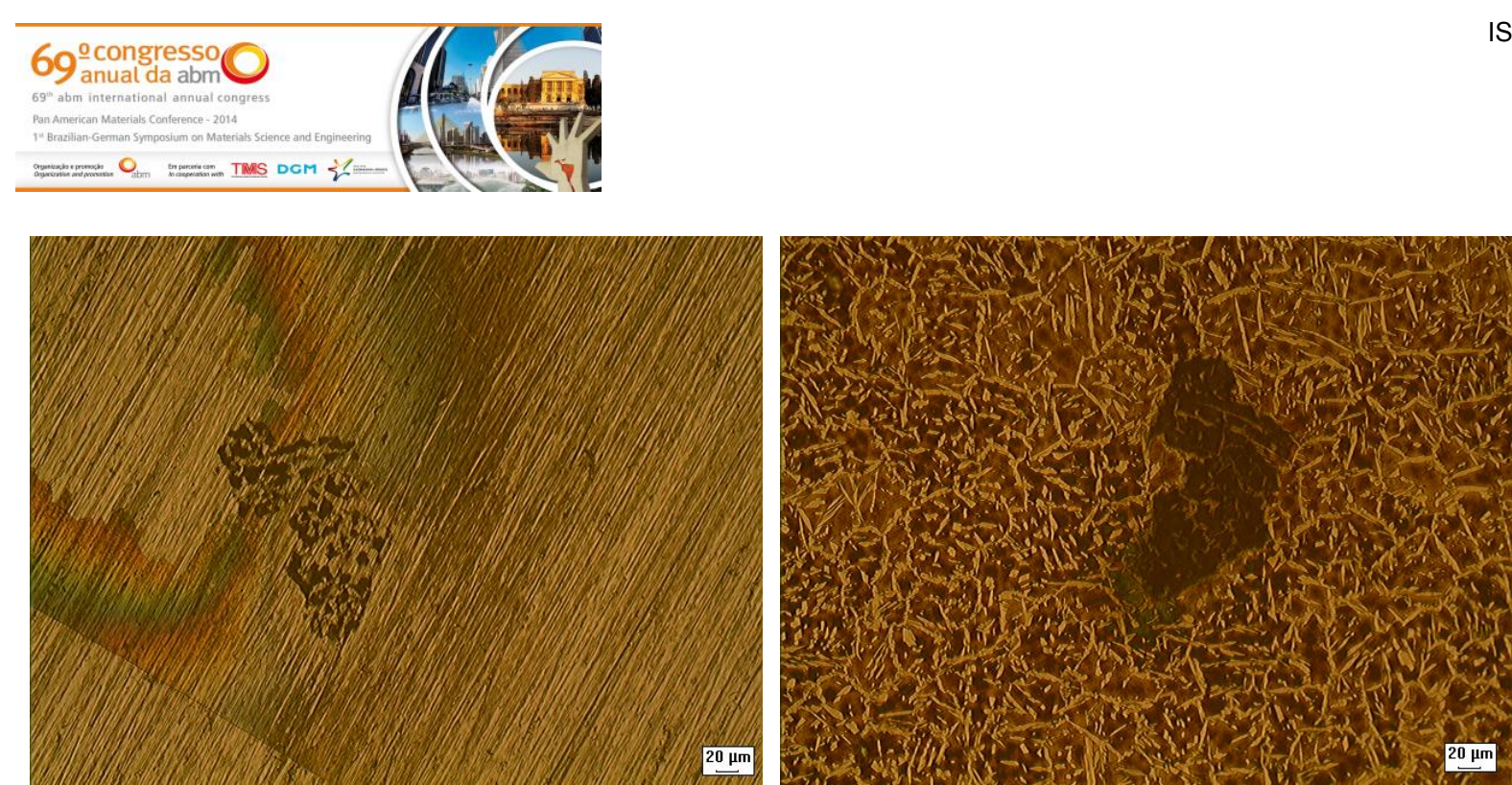

Figura 8. Micrografia do pite após o ensaio de CPT, condição I1V2. a) Lixado a 600 mesh, b) Polido. Ataque com behara modificado. Aumento de 200x.
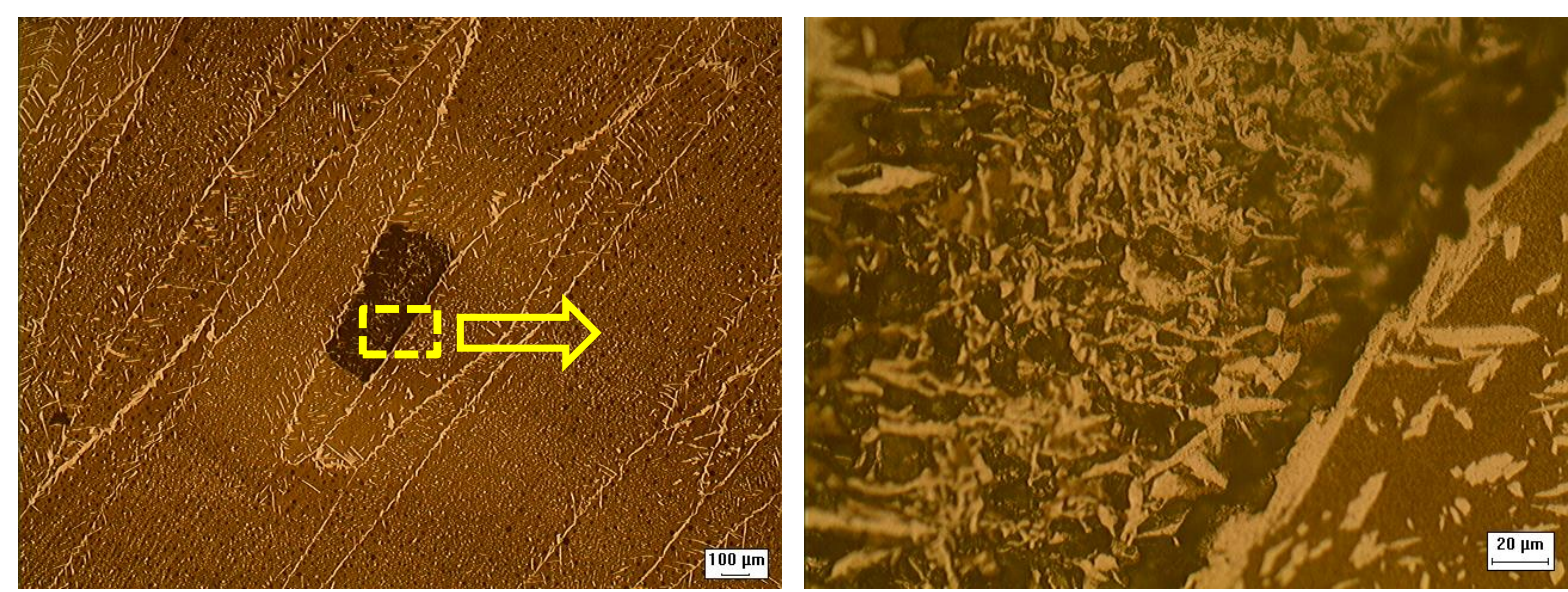

Figura 9. Micrografia do pite após o ensaio de CPT, condição I2V1. Polido e atacado com behara modificado. Aumento de: a) 50x e b) 500x.

Analisando as figuras 8 e 9, pode-se ver que o pite cresceu dentro do grão ferrítico e encontrou como barreira para expansão a fase austenita com morfologia alotrimórfica. Na Figura 9b (direita) pode-se ver, com foco no interior do pite, a austenita resistente à corrosão, mas aos redores vê-se a severa corrosão ocasionada na ferrita.

\section{CONCLUSÃO}

Tendo como base os resultados apresentados nas secções anteriores quanto à influência dos parâmetros de soldagem no balanceamento de fases e resistência à corrosão em aço inoxidável superduplex UNS S32750, pode-se concluir que:

- Foi verificado que a variação da energia de soldagem influenciou no balanço de fases e na resistência à corrosão.

- De modo geral, foi verificado nas soldagens de corrente contínua que o aumento da energia de soldagem proporcionou o acréscimo do teor de ferrita no metal de solda.

- O teor de ferrita influenciou na resistência a corrosão por pites negativamente, de modo que, quanto maior, menor a temperatura crítica de pite.

- A condição I2V2 obteve o pior resultado em CPT, mas também alto teor de ferrita e grande presença de precipitação de nitretos.

\section{Agradecimentos}

* Contribuição técnica ao 69 Congresso Anual da ABM - Internacional e ao 14ํㅡㄹ ENEMET - Encontro Nacional de Estudantes de Engenharia Metalúrgica, de Materiais e de Minas, 21 a 25 de julho de 2014, São Paulo, SP, Brasil. 




Os autores deste trabalho agradecem a CAPES e Petrobrás pela concessão das bolsas e financiamento do projeto, ao laboratório de corrosão da UFC pelos ensaios de corrosão CPT, à UFC em geral pela disponibilização do espaço e aos bolsistas do laboratório ENGESOLDA pela ajuda na realização deste trabalho.

\section{REFERÊNCIAS}

1 Lopes JTB. Influência da presença de fases frágeis e da temperatura nas propriedades de trinca por fadiga do aço inoxidável duplex UNS S31803. Tese de Doutorado, Departamento de Eng. de Materiais, Faculdade de Eng.

Mecânica, U. Estadual de Campinas.

2 Londoño AJR. Precipitação de fases intermetálicas e austenita secundária na ZAC de soldagens multipasse de aços inoxidáveis duplex." Tese de Doutorado Departamento de Eng. Metalúrgica, Escola Politécnica, U. de São Paulo, São Paulo, 2001.

3 Pohl M. The ferrite/austente ratio of duplex stainless steels. Zeitschrift für Metallkunde, München, 1995; 86(2): 97 - 102.

4 Nunes EB. Propriedades Mecânicas e Caracterização Microestrutural na Soldagem do Aço Inoxidável Duplex UNS S31803 (SAF 2205). Dissertação de Mestrado, Universidade Federal do Ceará Fortaleza, 2009.

5 Eckenrod JJ, Pinnow KE. Effects of chemical composition and thermal history on the properties of alloy 2205 duplex stainless steel. In: New Developments in Stainless Steel Technology. p. 77-87, 1984.

6 ASTM, Standard Test Method for Electrochemical Critical Pitting Temperature Testing of Stainless Steels - Designation G-150 99 (2010), 1999.

7 Garcia ERV. Efeito da corrente de soldagem do processo tig pulsado autógeno na microestrutura da zona fundida dos aços inoxidáveis duplex UNS S322101. Dissertação de mestrado, Escola Politécnica da Universidade Federal de São Paulo, 2011.

8 ASTM E 1245-03. Standard Practice for Determining the Inclusion or SecondPhase Constituent Content of Metals by Automatic Image Analysis.

9 Will CR. Comportamento à corrosão de juntas de superduplex UNS S32760 soldadas por GMAW pulsado com diferentes misturas gasosas. Dissertação de Mestrado, Universidade Federal do Rio Grande do Sul, 2009.

10 Kajimura $\mathrm{H}$, Ogawa $\mathrm{K}$, Nagano $\mathrm{H}$. Effects of $\alpha / \mathrm{\gamma}$ phase ratio and $\mathrm{N}$ addition on the corrosion resistance of Si-bearing duplex stainless steel in nitric acid. ISIJ International, 1991; 31(2): 216-222.

11 Ume K. et al. Influence of thermal history on the corrosion resistance of duplex stainless steel linepipe. Materials Performance, 1987; 26(8): 25-31, 1987.

* Contribuição técnica ao 69 Congresso Anual da ABM - Internacional e ao 14ํㅡㄹ ENEMET - Encontro Nacional de Estudantes de Engenharia Metalúrgica, de Materiais e de Minas, 21 a 25 de julho de 2014 , São Paulo, SP, Brasil. 